\title{
Enhancing Learning in Africa through Students' Collaboration with Parents, Teachers and Peers
}

\author{
Dainess Maganda ${ }^{1, *}$ \\ ${ }^{1}$ Comparative Literature Department, University of Georgia, Athens, Georgia, USA \\ *Correspondence: Comparative Literature Department, University of Georgia, 226 Joe Brown Hall, Athens, GA \\ 30602, USA. Tel: 1-706-542-9587. E-mail: magandad@uga.edu
}

Received: January 19, 2016

Accepted: March 7, 2016 Online Published: March 23, 2016

doi:10.5430/wje.v6n2p1

URL: http://dx.doi.org/10.5430/wje.v6n2p1

\begin{abstract}
Education scholars agree on the positive role that parents play in fostering educational success. Much research done also shows ways in which teachers contribute greatly to students' performance in school. Limited research focuses on how students' interactions with one another effect their academic performance. This study examines ways in which students were impacted by collaborating with their parents, teachers and with each other during a writing workshop in one elementary school in Northwestern Tanzania. Data seems to suggest that students accessed their parents' funds of knowledge; they became agents of change and used each other's academic input to improve their writing. Implications for research and teaching are discussed.
\end{abstract}

Keywords: parental involvement; students' engagement; collaboration; literacy

\section{Introduction}

For over a decade, education scholars have underscored the significant role parents play in their children's education (Jeynes, 2007). In fact, not only in developing countries, developed countries also cite parental participation to be among the major factors contributing to students' success in academia (Garcia-Reid, Peterson \& Reid, 2015). While income or social status are important factors, Henderson and Berla (1994) show that students' family's ability to "create a home environment that encourages learning, express high (but not unrealistic) expectations for their children's achievement and future careers, become involved in their children's education at school and in the community" (p. 160), is the most accurate predictor of student's accomplishment in school. Accordingly, therefore, numerous programs and policies focus on developing partnerships between families and schools to foster academic success.

In addition, the literacy practices teachers employ to impart knowledge within school institutions also matter significantly for optimal learning (Maganda, 2014, Epstein, 1991). More specifically, when teachers make learning at the center of their teaching by interacting positively with their students inside and beyond classroom walls, positive academic attainment is often the result (Maganda, 2015). While both, parental involvement and teacher participation are important for students' academic success, so often educators undermine the rather critical part played by the interactions that happen among students. This study examines the impact of having all three education stakeholders (students, teachers and parents) collaborate in a writing workshop to help students write books for their school library. Only a small portion of the data from this study is presented in this article.

The concept of parental involvement in this paper is defined as parental participation in the educational experiences and processes that their children undergo. This is a broad definition drawing from major research and theorizing on this topic (Epstein, 2001; Henderson \& Mapp, 2002). In addition, the paper highlights studies that focus not only on individual parental involvement; it also includes studies that look at programs facilitating parental participation in their children' academic success.

A review of literature mainly pertaining to parental involvement in children' education is presented first after which a few selected studies on teachers' educational contribution to students' learning is highlighted. A brief overview of key studies on students' engagement in school comes next and the methods employed in this study come thereafter. A presentation of the findings embedded with relevant discussion follows. 


\section{Review of Literature}

\subsection{Parental Involvement and Children's Education}

Research shows, parental involvement elevates educational outcomes especially for students facing a plethora of problems (Eccles \& Harold, 1993; Jeynes, 2005a; McBride \& Lin, 1996). Although Mattingly, Prislin, McKenzie, Rodriguez, and Kayzar (2002) study shows programs fostering parental participation having practically no impact on students' educational outcomes, when a more defined meta-analysis study is done, such as that by Fan and Chen (2001), the conclusion is that parental contribution positively influences educational outcomes. In addition, the Mattingly et el. study omitted critical studies on this topic, such as Koskinen, Blum, Bisson, Phillips and Creamer (2000), Miedel and Reynolds (1999) as well as Sanders (1998), Shaver and Walls (1998) who all came to the same conclusion, parental participation betters students' performance in school.

More specifically, among other studies (Downer, Campos, McWayne, \& Gartner, 2010; Jeynes, 2013; Lamb \& Lewis, 2010; Palm \& Fagan, 2008), and more recently, Jeynes (2015) shows a significant association between father involvement and the educational outcomes of youth, both white and minority children. Having both parents participate to make sure their children do their homework improves grades in mathematics (Mundt, Gregory, Melzi \& McWayne, 2015). When families engage with their children's school (e.g., visiting the school, communicating with teachers, volunteering at school events), their children tend to make academic gains - a finding that has been replicated across numerous studies (Fan \& Chen, 2001; Hill \& Tyson, 2009). In South Africa, Msila (2012) highlights how parents not only participate in their children's learning process but also educational scholars are examining whether parental involvement may also enhance school management, which is an important factor to students' academic achievement.

Epstein (1995), Lemmer (2007) and Jeynes (2010), to name just a few, found that parents prefer to be involved in their children's learning instead of them taking part in school governing bodies. As such, Borgonovi and Montt (2012) illustrate students succeed in school when their parents talk to them about school, especially what they have learned. Tornblad and Widell (2014) show parental involvement differs significantly internationally based on gender, age and cultural expectations. Pertinent to this study, in Tanzania, Kapinga (2014) establishes that many parents desire to take part in their children's education although their socio economic status (SES) determines their level of involvement. Zedan (2012) and Wabike (2012) found most students in Tanzania perform well in school when their parents believe in the importance of school and encourage them to attend school daily. In another East African country, Kenya, completion of students' homework has been attributed to their mothers' active monitoring and reinforcement (Ogoye-Ndegwa, Mengich \& Abidha, 2007). In spite of all studies showing positive effect of parental involvement to students' academic achievement, several obstacles are also cited such as low educational level among parents' (Ogoye-Ndegwa, Mengich \& Abidha, 2007), and parents not knowing how to help their children with school work (Borgonovi \& Montt, 2012). In all, it is difficult to dispute the major claims that parental involvement significantly affects children's success in school.

\subsection{Teachers' Educational Contribution to Students' Learning}

There is no doubt teachers contribute greatly to ways students learn. However, Otula (2007) underscores that effective learning embroils collaboration of students, teachers as well as parents. Teachers play a key role in cultivating students' engagement in school (Akey, 2006). By using collaborative learning and allowing students to use experiential learning, teachers are able to increase students' engagement in learning (Heller, Calderon \& Medrich, 2003). Research shows, students are more likely to pay attention in class and achieve highly academically if their teachers were supportive and cared about their success (Heller et al., 2003; Akey, 2006).

For Latino students for example, Mundt, Gregory Melzi and McWayne (2015) study demonstrate that good grades in ethnic math was connected to having a Latino teacher explain and work together with parents in school-based family engagement. When teachers value parents and make them feel welcome at school, parents and caregivers tend to participate in school activities as well as follow-up on their children's academic progress (Anderson \& Minke, 2007; Walker, Ice, Hoover-Dempsey \& Sandler, 2011). Also, Luis Moll, Cathy Amanti, and Norma Gonzalez (2005) argue that when teachers take the time to learn and tap into their students' families and community's knowledge and resources, funds of knowledge, learning is greatly enhanced.

In a 3-year longitudinal study examining the impact of teacher support within and beyond school walls, Hughes, Luo, Kwok and Loyd (2008) indicate students attained higher grades in all subject areas based on the type and level of support received from their teachers. Specifically, it is easy to predict ways in which parents are involved in their children's education when teachers assign homework intended to increase student-parent interactions, hold 
workshops for families, and communicate to parents about their children's education (Dauber \& Epstein, 1993). But having teachers support students and guide them in their learning process is not enough. Students need each other.

\subsection{Student Engagement in School}

In addition to parental and teachers involvement, even more important, studies show positive student participation in the classroom is critical in increasing students' achievement (Akey, 2006; Heller, Calderon, \& Medrich, 2003; Garcia-Reid, Reid, \& Peterson, 2005). Peer collaboration among students significantly impacts students' academic performance (Otula, 2007). Nelson and DeBacker (2008) examined factors that motivate adolescents to attain high grades in school. Their study demonstrate that peers and best friends make a significant difference; the climate they create in the classroom through verbal and non-verbal communication in particular, affects how well students perform academically.

In a research study examining the achievement gap between white and black youths, especially in middle school because of the general deterioration in school commitment and academic achievement at this age level, Darensbourg and Blake (2014) noted that achievement values significantly predicted students' engagement while also engagement predicted achievement among Black adolescents. Even more, their study points out both peer and parental involvement impacted these processes. In the classroom for example, Marks (2000)' research reveals that practices teachers employ in structuring instructional activities to allow students to engage in the learning process affects their performance from elementary, middle, and even more during their high school years.

\section{Theoretical Framework}

\subsection{Cultural Psychology}

One of the main advocates of the field of psychology, Richard Shweder (1991), defines cultural psychology as "The study of the way cultural traditions and social practices regulate, express, and transform the human psyche, resulting less in psychic unity for humankind than in ethnic divergences in mind, self, and emotion" (p. 72). In other words, this branch of psychology focuses on how culture, tradition and social practices impact human consciousness. Michael Cole (1998) writes that the underpinning of cultural psychology is that the way people think is tied to their cultural background. Cole underscores the following characteristics of cultural psychology pertaining to literacy and research. First, cultural psychology emphasizes mediation through artifacts or in other words interceded action in a context. This means cultural psychology seeks to ground analysis in daily life events; assumes individuals to be active in their own development even in settings they did not choose entirely. This idea led the author to look at discrete contexts of events within social interactions inside the students' communities with their parents and their teachers.

Another tenet of cultural psychology is that people exercise historical development which entails the making, using, rearranging and rediscovering of tools from subsequent generations through the process of enculturation. Thus, culture is understood as accumulated artifacts of a group and a medium of human development. Accordingly, the author used this idea to understand areas of students' literacy development in light of how teaching was done during the writing workshop and the opportunity that was created in order to enable students to draw from their experiences and their parents' knowledge, as well as the history of what "counted" as education for previous generations of learners. Additionally, cultural psychology analyzes human psychological functions and necessitates that a person understands the everyday activities people involve themselves in, and that analysis has to be grounded in people's practical activities. Hence, the writing workshop was designed to allow the creation of books to take place not only at school but also at home whereby parents assumed their daily activities as they usually do while students interact with them based on instructions sent from their teachers.

In addition to cultural psychology, the author employed a socio-cultural theory in this study because it provides avenues to make sense of students' learning. However, it falls short of bringing aspects of identity, power and agency in literacy research practitioners, aspects that were part and parcel of this study. Other educators likewise have encountered varied limitations of this theory to meet the needs of their research, thus a decision to use a critical socio-cultural perspective.

\subsection{Critical Socio-cultural Research in Literacy}

To understand literacy as a social and cultural practice, scholars who have taken literacy research as a form of activism to address issues of social justice and practices that serve marginalized groups of people, find it necessary to bring a critical concept to socio-cultural theory. They combine socio-cultural theory and critical literacy theory as conceptual frameworks that allow them to forge social transformation with a potential to impact policy in 
institutional practices. In addition to believing in literacy as historically, socially, and culturally situated, they posit that "learning and literacy are shaped by power, identity and agency" (Lewis, Enciso \& Moje, 2007, p. ix). Specifically, to reframe socio-cultural research, these researchers focus on ways that literacy events and practices are tied to the central role of language and discourses within society. Likewise, one of the reasons the author took a critical socio-cultural stance for this exploration was the desire to question and explore languages and discourses within the school and community of the study.

For example, with an aim to learn how daily interactions between students and teachers as well as the organization and structure of the schooling institution, constrain and support youth's opportunities to learn; Moje and Lewis (2007) analyzed a small portion of one classroom transcript by using critical socio-cultural research to examine how power continues to be reproduced in everyday interaction. They also looked at ways in which people's possibilities for daily interactions are framed by large-scale power differentials.

Patricia Enciso (2007) used a similar theory to analyze data from a research project that looked at ways gender was represented in historical fiction. Socio-cultural theory itself perceives history as unified, accessible, inclusive and stable. However, when taken from a critical point of view, history is never final, complete or in the past, rather, history is a cultural resource engulfed with limitations and possibilities.

Enciso's analysis helps the author demonstrate how the three education stakeholders in this study - students, parents, and teachers - were led to see how history is a cultural resource with potential to reveal ways in which inequitable power relations are culturally produced through historical narratives. Following in their footsteps, the author also brought in a critical stance in this inquiry in order to grapple with how schooling in Tanzania positions students as learners and members of their societies and what happens when they are given opportunities to exercise agency through language use as co-learners, teachers and text producers within a writing workshop framework.

\subsection{A Critical Perspective of Literacy}

A critical literacy theory considers literacy to be social action through language use. People learn to read and write to become conscious of their experiences and to be agents of change in their specific cultures, cultures that are historically constructed within specific power relations (Luke, 1993). This perspective involves the examination and critiquing of how texts, language, power, social practices and social groups relate (Janks, 2010). The use of this stance was helpful in guiding students to become agents of social change by developing their use of language as social action. Though the author did not explicitly guide students to address their social issues, believing in this stance and having it in her mind resulted in encouraging students to explore their social issues by letting them write about issues important to them. Also, the author showed them how texts can be used to bring social equity and change. Consequently, this stance became a way to explain how students could use language as social action to make their communities better.

In particular, Freire's (1970) concept of praxis was employed. Praxis is a process of enacting, practicing, embodying or realizing a theory, lesson, or skill. Freire defines praxis in Pedagogy of the Oppressed (1970) as "reflection and action upon the world in order to transform it" (p. 9). Shor and Pari (1999) explain that praxis is "a close relationship between words and action, between the symbolic and the concrete-theorizing practice/practicing theory" (p. 15). It also refers to the act of engaging, applying, exercising, evaluating, reflecting on ideas through which people gain power and understanding on how to take action against oppression (Gadotti, 1994).

Using the concept of praxis was instrumental in examining how all participants (students, teachers and parents) reflected upon and articulated their social issues during this study. Furthermore, the use of this viewpoint was instrumental for the author to bring understanding on ideas and issues the participants expressed as a result of their experience of collaboratively creating texts during this study. Specifically, the analysis of students' interactions with each other showed the process of reflection through praxis. The reflection to which the author alludes here can be understood to capture ideas of reflectivity and reflexivity. Wilhelm (2009) explains that while reflectivity means the ability to make meaning in and of particular circumstances through the use of one's own values, habits, processes, and experiences; reflexivity on the other hand means stepping outside one's own common way of seeing and knowing, reflecting upon their social issues, and/or taking some action in order to transform their society.

\section{Methods}

The study was done at Manyara Primary school (Pseudonym) in the Northwestern part of Tanzania. Tanzania is a multilingual country with more than 120 ethnic groups (Paul, Simons, \& Fennig, 2015). While it is the only national language in Tanzania, Swahili is also one of the official languages with English taking the same position in Tanzania 
(Godfrey, 2014). Basically, English seems to be considered more of an academic language while most people tend to use Swahili for their daily communication. Hence, Swahili unites all Tanzanians; it is also used as the language of instruction in primary schools and just recently, Tanzania decided to replace English which was the language of instruction in secondary and tertiary school, with Swahili as the medium of instruction in secondary level as well (Macha, 2015; Mohammed, 2015).

Similar to most African countries, writing instruction in Tanzania is done in language arts classes (Graham \& Perin, 2007). Teachers often take the center stage with little interaction taking place with students in small groups; students often work independently. Writing instruction focuses on the mastery of grammar; consequently, it is divorced from students' lives (Maganda, 2014). Students write to answer questions from passages or fill-out grammar activities from their textbooks. The writing workshop model was used in this study because it is used in multilingual classrooms; it allows students to write with a purpose and with a sense of audience; and it lets students master writing skills while giving them the opportunity to use their lives as resources for their writing. More importantly, students are given opportunity to involve their parents depending on the issues they want to address through their writing.

The entire study took three months. Out of those months, the writing workshop was conducted in one month involving one hundred and nineteen $6^{\text {th }}$ graders with their Swahili and English teachers, although other teachers also helped from time to time, making a total of 19 teacher participants. All teachers had taught for more than 5 years with most of them having taught for at least 10 years. Among all teachers, only two attended a professional development seminar within the past 10 years. The study involved 19 parents who mostly spoke Sukuma, the local ethnic language in the Manyara community. More than $50 \%$ of the parents were farmers while others were businessmen and women. A small number of them were medical doctors and teachers. As mentioned earlier, Swahili, the national language in Tanzania united all participants who came from varied ethnic backgrounds namely: Nyiramba, Ruli, Haya, Hehe, Matta and Nyaturu.

Even though parents helped their children at home, students, with help and guidance from their teachers, including the author, did most of their wiring at school. Due the large number of all six graders, teachers helped to put students in 16 groups with each aiming to write one book. Students could use any language they wanted or mix between Swahili, English and their ethnic languages. This linguistic freedom was permitted in order to encourage students to write without any linguistic barrier while also enabling them to inquire any information from their parents. After the workshop, meetings with parents, teachers and students were conducted. Due to cultural standards, which for the most part discouraged youngsters to express their opinions or ideas in front of adults, the meetings, where interviews occurred were done separately (i.e., parents alone, teachers alone and students alone) in order to enable students to express their ideas freely. Only once, at the request of students, one meeting was conducted with teachers and students. In this article, only a portion of this study's impact on students is presented.

\section{Findings and Discussion}

A thematic approach to data analysis was used. The data seems to suggest that the writing workshop repositioned students' interactional patterns in three different ways. It changed the way they interacted with their parents, their teachers and with each other. By examining how students interacted with their parents during the workshop, the noticeable changes that occurred among students the author called, students accessed their parents' funds of knowledge. When students communicated rather differently with their teachers, the author called that, students became agents of change. The data revealing students working together with their peers and the impact of such interaction, the author called that, students used each other's academic input to improve their writing.

As mentioned earlier, typical writing in Tanzania does not allow parents to contribute in their students' learning process as most of the writing focuses on developing grammar skills. Such instructional model hindered parental involvement in their children's learning. Specifically, the writing instruction did not give students the opportunity to learn from their parents and each other. Students mainly learned from their teachers, which in turn, positioned them as recipients of information and with no sense of agency pertaining to school. By looking at the data on ways students interacted with parents, teachers and each other, new interactional patterns became apparent.

\subsection{Students Accessed Their Parents' Funds of Knowledge.}

As indicated in the literature, when teachers give students assignments that encourage interaction with their parents, often parents get involved. Therefore, with a goal to facilitate involvement and collaboration between parents and students, the author encouraged students to ask their parents for information on topics they didn't know or had 
limited knowledge. As shown earlier, funds of knowledge are the home and community resources of students (González, Moll, \& Amanti, 2005). Data suggests students repositioned their parents as history teachers and medical experts.

\subsubsection{Students Repositioned Their Parents as History Teachers}

During the workshop, students explored varied topics including some that led them to inquire information from their parents. For example, some groups wrote about the history of their school and some about diseases such as malaria and HIV. For those writing on the history of their school, they asked their parents to share what they knew about how their school came into being. Below see a comment from one parent who shared during the interview regarding his son inquiring information about how the school began. His son was part of group $\mathrm{M}$, which was writing a book about the history of the school.

I was surprised that for the first time my son came and asked me, 'So how did this school happen to be called Manyara and what about that mountain there, does it have anything to do with this school?' And then he (the son- Paulo) asked, 'Where the school was first built...?' I started wondering, for all six years of schooling, he has never asked me this before, and where did he get that question? (Mashaka, 2010).

Mashaka's comment is illustrative of the interactions that happened between students and parents. Mashaka's son Paulo was able to inquire from his father about the history of his school for the very first time. As expressed, Mr. Mashaka was surprised that he has never been asked this question by his son although he already attended school for six years. It was the instructional approach, the writing workshop in particular that facilitated this type of interaction and by doing so, children such as Mashaka's son were able to use their parents as history experts with the ability to pass down what they know to their children (Cole, 2010). In turn, rather than conversing with them as parents and caregivers only, this time, students such as Paul repositioned them as history teachers.

One student, Sikola, whose group also wrote a book about the history of Manyara commented on how he benefited from his parents' knowledge. He reported:

I learned a lot from my parents when I was writing. They know a lot about the past and their life experience was so useful for my writing. They know a lot about what happened here, like how our school began. They also seem wiser than us; they were so helpful especially in explaining how our school was started in light of current events in contrast with the past. They seem to see things in a big picture (Sikola, 2010).

In this example, Sikola highlighted the knowledge the parents held. When Sikola expressed that he learned a lot from his parents, he underscored the knowledge exchange which took place between the children and parents. Furthermore, Sikola gave a rather definitive statement which compared the younger generation and the older generation. He said the parents were "Wiser" than they are. His confession was followed by an explanation that parents can explain things through double perspectives, the past and current. Sikola acknowledged that parents are therefore able to see things in a big picture. This description demonstrates how the writing workshop allowed students to involve their parents on specific historical matters which in turn enhanced their writing. Parents on the other hand also responded to their children' requests and contributed their knowledge accordingly, and by doing so, they used their funds of knowledge to enhance students' learning.

\subsubsection{Students Repositioned Their Parents as Medical Experts}

In one of the groups that wrote about HIV, the father of one of the students named Julius was a medical doctor. Julius reflected on the type of knowledge his group received from their parents:

I really enjoyed working with my parents because when our group was writing about HIV AIDS, we didn't know a lot about its history. I asked my parents and my friends did too. Our parents told us about the history of this disease- we didn't know. We then included that information in our book (Julius, 2010).

Similar to Mashaka's son who asked his parents questions about the history of Manyara primary school, likewise, Julius also inquired from his parents regarding HIV. Both examples illustrate ways the writing workshop repositioned students' way of interacting with their parents, hence exemplifying the passing down of knowledge from one generation to another (Cole, 1996). They were able to treat them as knowledge givers because the teachers encouraged them to do so.

\subsection{Students Became Agents of Change}

As expressed earlier, critical literacy helps people understand ways to take action to transform their communities (Freire, 1970; Janks, 2000). The writing workshop created the conditions for students to take action to better their 
community by facilitating reflection upon and action regarding their social issues regardless of power structure (Janks, 2010). In the process, they disrupted the status quo in their school community by taking an agentive stance with teachers. In particular, they asked teachers to allow them to continue creating books and to make their writing public. This agentive stance violated educational and cultural norms of teachers telling students what to do rather than students taking the lead in expressing what they want to see done regarding school matters.

\subsubsection{Students Asked to Continue Creating Books}

In one of the meeting held after the writing workshop, among other matters, students and teachers talked about what they would like to see after the workshop. Many students expressed their desire to continue writing books. The following comment by one student, Jonathan was typical. Jonathan said:

I think it will be a good idea for the teachers to plan a special meeting to discuss with us about ways in which the writing of books can be part of the current curriculum. I would like to see that we continue learning to write and we actually keep on creating books. They (teachers) can talk separately first but I think it will help if they also give us the opportunity to think with them on this (Jonathan, 2010).

The unusual sense of agency here was that Jonathan took an authoritative role by calling teachers to action. "I think it will be a good idea for the teachers to plan a special meeting." He continued to express his desire by again using a first person singular, "I would like to see that we (students) continue learning to write and we actually keep on creating books..." Jonathan's use of the first person pronoun, I, put him on the active and commanding role, an unusual role for a student to play in a Tanzanian education system. He continued to give details on what he would like to see happen, "Teachers can talk separately first" but also spoke on behalf of other students by including himself with other students, "Give us (students) the opportunity..." while putting himself in an equal level with the teachers, "To think with them (teachers) on this." Jonathan therefore took action by telling the teachers what to do and in the process; he repositioned himself differently from the usual interaction he and other students have with teachers.

In addition, Jonathan encouraged his teachers to think with them on this matter. As previously discussed, teachers often tell students what to do but in this remark, students, Jonathan in this case, was asking to become somewhat on the same level with teachers as a thinker and active participant on taking actions to better their school.

\subsubsection{Students Encouraged Their Teachers to Make Their Writing Public}

Similar to previous data, more students continued to display activism by calling teachers to action and in this case, they asked teachers to organize a community event so that their books would be read publicly in their school community. For example, another student, Thomas, said:

"I would like for the school to find ways to assemble the community to read our books. I will really like our books to be read not only at our school but also in our community. So, teachers, please find ways to get others to read our books."

Once again, students such as Thomas took an active role in letting their teachers know their desire to have their books read beyond school walls. Similar to Jonathan, Thomas used the first person singular, "I would like the school..." implying he was speaking for himself. He was very specific about what he wanted the school to do and in that sense; he was using language to take actions. As such, Thomas made sure the teachers understood the scope of publicity he was looking for, "Not only at our school but also in our community." At the end, lest anyone misunderstand what he wanted, he clarified what he meant by "school" by actually naming the recipients of his call to action, "Teachers, please find ways to get others to read our books." Even though this sentence is prefaced with the word please, there is no doubt that it is also a directive request to action. By asking teachers to find ways to get others to read the students' books, Thomas disrupted the teachers' historical and cultural status quo of power.

The changed interactional patterns between students and teachers illustrate a critical literacy stance whereas students stepped outside of their own common way of seeing and doing, and intentionally reflected upon their social issues, which in this case was the need to create books in the future and to have those books read publically in their community. By doing so, they took actions to transform their society (Wilhelm, 2009). This was not the only interactional change; they also treated each other as academic resources for their writing.

\subsection{Students Used Each Other's Academic Input to Improve Their Writing}

Typically, students work independently to answer questions in their workbooks. The type of interactions in the classroom is often that of a teacher with the whole group or a teacher asking questions expecting a response from one student at a time. Since students often do not work in groups, they are not accustomed to thinking together or sharing 
ideas that enhance each other's learning. Drawing from a social perspective of literacy, learning is a process that does not take place in an individual's mind but rather within a participation framework. The author intentionally created a workshop that allowed learning to be mediated by the interaction and perceptions of co- participants. As a result, students changed the way they interacted with each other during the workshop. Specifically, they negotiated on the major issues to write about and the content of their books.

\subsubsection{Students Negotiated the Major Issues to Write About}

In each of the sixteen groups, students contributed ideas on what each book was to be about. Consider this exchange among students in one group.

John: Let's write about our school

Susana: What is there to write about school? Besides, I know the other group is doing that. Why don't we write about orphan children so those rich people will do something helpful to them?

John: Maybe you are right. What do you all think? Teacher, help us too.

Teacher Magdalena: I am listening to your ideas; can you combine both of your ideas to write your book?

Susana: Maybe we could say that our school has a lot of orphan children as a way to start our book...

Anna, Mary, Gido and John: Yes, we should combine the two.

As mentioned earlier, the writing workshop created an environment through which the students had a chance to learn with and from each other about important issues in their lives. The interactions seen here, for example, John thinking through what to write about and then Susana bringing another idea she felt more important exemplified ways in which the writing workshop positioned students to learn with each other, and by doing so, students treated each other as co-participants in the learning process rather than co-recipients of knowledge poured down from their teachers. Not only in choosing the main issue of their books, students also worked together to determine the details in their books.

\subsubsection{Students Negotiated the Content of Their Books}

Similar to the above process on choosing the main issue of focus for each book, in all sixteen groups, students negotiated what needed to be in the book. Sometimes they questioned each other's understanding of a particular issue and sometimes they just solicited more information. In group F, for example, when writing a first draft on their book about malaria, they talked about and negotiated what needs to be included in their books.

Tabu: Everybody here knows malaria. We should begin our book by saying that a friend of ours got malaria because she did not sleep under a mosquito net.

Shisoji: So are you saying that all people who get malaria do not sleep under a mosquito net?

Tabu: Not necessarily, but I am saying one way people get malaria is by not sleeping under a mosquito net.

Shija: Not everybody who gets malaria did not sleep under a mosquito net, but everybody with malaria was bitten by a mosquito. So how should we make this point?

Shisoji: Why don't we start the book like Tabu said and then in the book we write how this friend of ours had to be hospitalized. During the time in the hospital, a doctor comes to explain that Malaria is caused by mosquito bites but mosquitoes come because of letting grasses grow too tall or because of stagnant water. When mosquitoes are around, people can avoid being bitten by sleeping under mosquito nets and other strategies.

Tabu and Shija: We agree with your idea Shisoji.

In the above example, it was clear that each student knew something about malaria. Tabu's idea that her friend got malaria by not sleeping under a mosquito net caused the three of them to clarify to each other the facts about the cause, spread and prevention of malaria. They demonstrated a critical socio- cultural perspective of literacy in action by interacting about book content, a pattern not usually employed at their school and in Tanzania in general. In the end, a process of reflection was going on among students as they critically thought about Malaria, a social aspect of their daily lives. As such, students were making meaning in and of particular circumstances through the use of their own values, habits, processes, and experiences (Moje \& Lewis, 2007; Wilhelm, 2009). 


\section{Conclusion}

Over the years, history testifies of the power that comes from people working together. Without undermining how parental involvement affects academic performance while also acknowledging teachers' role in facilitating learning outcomes, this study shows student-to-student interaction contributes greatly to academic success. The writing workshop was a literacy practice unfamiliar to the Tanzanian education system. However, it is this uncommon practice that allowed students to take unusual positions in interacting with their parents, their teachers and each other in ways that exhibited enriched learning. The shift in their interactional patterns allowed students to draw from the resources inherently present in their community and to practically apply their knowledge to social issues pertinent in their school community.

More importantly, this study shows how parents who often don't participate in their children's learning do so when teachers design literacy activities that permit them to keep their cultural positions as knowledge givers on historical and cultural matters. Likewise, students sought guidance and worked with their parents when encouraged to do so. Although students knew and were accustomed to following directions from their teachers, they were able to act against that norm by expressing their desires to continue writing books and urging their teachers to publicize their books. This stance didn't happen overnight. It was a transformational process that took place slowly as students got comfortable to collaborate with their teachers throughout the writing workshop.

This study shows what is possible when educators take the initiative to foster collaborations among different education stakeholders even for a short period of time. More research needs to be done to see long term outcome of studies fostering such collaborations in more than one class and for a longer periods of time. As a way to continue improving and enhancing the quality of education in Africa, literacy scholars ought to examine ways in which literacy practices may foster collaboration among varied education stakeholders while fostering practical application of the knowledge inherently present in their communities and allowing students opportunities to have a sense of agency to better their societies.

\section{References}

Akey, T. M. (2006). School context, student attitudes and behavior, and academic achievement: An exploratory analysis. New York: MDRC.

Anderson, K. J., \& Minke, K. M. (2007). Parent involvement in education: Toward an understanding of parents' decision making. Journal of Educational Research, 100, 311-323. http://dx.doi.org/10.3200/JOER

Borgonovi, F., \& Montt, G. (2012). Parental Involvement in Selected PISA Countries and Economies. OECD Education Working Papers, No. 73. OECD Publishing. http://dx.doi.org/10.1787/5k990rk0jsjj-en

Cole, M. (1998). Can Cultural Phycology help us think about Diversity? Mind, Culture, and Activity, 5(4), 291-304. http://dx.doi.org/10.1207/s15327884mca0504_4

Cole, M. (2010). Online. Can Cultural Phycology help us think about Diversity. Mind, Culture and Activity, 5(4), 291-304. http://dx.doi.org/10.1207/s15327884mca0504_4

Darensbourg A. M., \& Blake. J.J. (2014). Examining the Academic Achievement of Black Adolescents: Importance of Peer and Parental Influences. Journal of Black Psychology, 40(2), 191-212. http://dx.doi.org/10.1177/0095798413481384

Dauber, S.L., \& Epstein, J. L. (1993). Parents' Attitudes and Practices of Involvement in Inner City Elementary and Middle Schools. In Families and Schools in a Pluralistic Society (Ed.), Nancy F. Chavkin. Albany: State University of New York Press.

Downer, J. T., Campos, R., McWayne, C., \& Gartner, T. (2010). Father involvement and children's early learning: A critical review of published empirical work from the past fifteen years. In W. Jeynes (Ed.), Family factors and the educational success of children (pp. 64-105). New York, NY: Routledge.

Eccles, J. S., \& Harold, R. D. (1993). Parent-school involvement during the early adolescent years. Teachers College Record, 94, 568-587.

Epstein, J. (2001). School, family, and community partnerships. Boulder, CO: Westview.

Epstein, J.L. (1991). Effects on student achievement of teachers' practices of parent involvement. Advances in Reading/Language Research, 5, 261-276.

Fan, X., \& Chen, M. (2001). Parental involvement and students' academic achievement: A meta analysis. 
Educational Psychology Review, 13(1), 1-22. http://dx.doi.org/10.1023/A:1009048817385

Garcia-Reid, P., Peterson, C.P., \& Reid, R. J. (2015). Parent and Teacher Support among Latino Immigrant Youth Effects on School Engagement and School Trouble Avoidance. Education and Urban Society, 47(3), 328-343. http://dx.doi.org/10.1177/0013124513495278

Garcia-Reid, P., Reid, R., \& Peterson, N. A. (2005, May). School engagement among Latino youth in an urban middle school context: Valuing the role of social support. Education and Urban Society, 37(3), 257-275. http://dx.doi.org/10.1177/0013124505275534

González, N., Moll, L., \& Amanti, C. (2005). Funds of Knowledge: Theorizing Practices in Households, Communities, and Classrooms. New Jersey: Lawrence Erlbaum Associates, Publishers

Graham, S., \& Perin, D. (2007). A Meta-Analysis of Writing Instruction for Adolescent Students. Journal of Educational Psychology, 99(3), 445- 476. http://dx.doi.org/10.1037/0022-0663.99.3.445

Heller, R., Calderon, S., \& Medrich, E. (2003). Academic achievement in the middle grades: What does research tell us? A review of the literature. Atlanta, GA: Southern Regional Education Board.

Henderson, A. T., \& Berla, N. (Eds.). (1994). A new generation of evidence: The family is critical to student achievement (A report from the National Committee for Citizens in Education). Washington, DC: Center for Law and Education.

Henderson, A. T., \& Mapp, K. L. (2002). A new wave of evidence: The impact of school, family, and community connections on student achievement. Austin, TX: Southwest Educational Development Laboratory.

Hill, N. E., \& Tyson, D. F. (2009). Parental engagement in middle school: A meta analytic assessment of the strategies that promote achievement. Developmental Psychology, 43, 740-763. http://dx.doi.org/10.1037/a0015362

Hughes, J., Luo, W., Kwok, O., \& Loyd, L. (2008). Teacher-student support, effortful engagement, and achievement: A 3-year longitudinal study. Journal of Educational Psychology, 100, 1-14. http://dx.doi.org/10.1037/0022-0663.100.1.1

Jeynes, W. (2013). Father involvement, African Americans, and reducing the achievement gap. In J. Pattnaik (Ed.), Father Involvement across the globe (pp. 71-87). Amsterdam, The Netherlands: Springer. http://dx.doi.org/10.1007/978-94-007-5155-2_5

Jeynes, W. H. (2002). Divorce, family structure, and the academic success of children. New York: Haworth. http://dx.doi.org/10.1177/0042085906293818

Jeynes, W. H. (2007). The Relationship Between Parental Involvement and Urban Secondary School Student Academic Achievement: A Meta-Analysis. Urban Education, 42(1), 82-110.

Jeynes, W. H. (2010). Parental involvement and encouraging that involvement: Implications for school-based programs. Teachers College Record, 112(3), 747-774.

Kapinga, O. S. (2014). The Impact of Parental Socioeconomic Status on Students' Academic Achievement in Secondary Schools in Tanzania. International Journal of Education, 6(4), 120-132. http://dx.doi.org/10.5296/ije.v6i4.6420

Koskinen, P. S., Blum, I. H., Bisson, S. A., Phillips, S. M., \& Creamer, T. S. (2000). Book access, shared reading and audio models: The literacy learning of linguistically diverse students in school and at home. Journal of Educational Psychology, 92(1), 323-336. http://dx.doi.org/10.1037/0022-0663.92.1.23

Lamb, M., \& Lewis, C. (2010). The development and significance of father-child relationships in two-parent families. In M. Lamb (Ed.), The role of father in child development (5th ed., pp. 94-153). Hoboken, NJ: Wiley.

Lemmer, E.M. (2007). Parent involvement in teacher education in South Africa. International Journal about Parents in Education, 1(0), 218-229.

Macha, N. (2015). Tanzanian Schools will teach students in Swahili, Not in English. Global Voices. Retrieved from https://globalvoicesonline.org/2015/02/24/tanzanian-schools-will teach-students-in-swahili-not-english/

Maganda, D. (2014). Empowering Students in Africa for Social Activism through Action research. American International Journal of Contemporary Research, 4(10), 31-40.

Maganda, D. (2015). Repositioning Teachers for Optimal Learning in Africa through Action Research. Journal of 
Gender and Information and Development in Africa (JGIDA), 3(1\&2), 37-55.

Marks, H. M. (2000). Student engagement in instructional activity: Patterns in the elementary, middle, and high school years. American Educational Research Journal, 37, 153-184. http://dx.doi.org/10.3102/00028312037001153

Mattingly, D. J., Prislin, R., McKenzie, T. L., Rodriguez, J. L., \& Kayzar, B. (2002). Evaluating evaluations: The case of parental involvement programs. Review of Educational Research, 72(4), 549-576. http://dx.doi.org/10.3102/00346543072004549

McBride, B. A., \& Lin, H. (1996). Parental involvement in prekindergarten at-risk programs: Multiple perspectives. Journal of Education for Students Placed at Risk, 1(4), 349-372. http://dx.doi.org/10.1207/s15327671espr0104_5

Miedel, W. T., \& Reynolds, A. J. (1999). Parent involvement in early intervention for disadvantaged children: Does it matter? Journal of School Psychology, 37(4), 379-402. http://dx.doi.org/10.1016/S0022-4405(99)00023-0

Mohammed, O. (2015). Tanzania dumps English as its official language in schools, opts for Kiswahili. Quartz. Retrieved

from http://qz.com/355444/tanzania-dumps-english-as-itsofficial-language-in-schools-opts-forkiswahili/

Msila, M. (2012). Black Parental Involvement in South African Rural Schools: Will Parents Ever Help in Enhancing Effective School Management? Journal of Educational and Social Research, 2(2), 303-313.

Mundt, K., Gregory A., Melzi G., \& McWayne, C.M (2015). The Influence of Ethnic Match on Latino School-Based Family Engagement. Hispanic Journal of Behavioral Sciences, 37(2), 170-185. http://dx.doi.org/10.1177/0739986315570287

Nelson, R. M., \& DeBacker, T. K. (2008).Achievement motivation in adolescents: The role of peer climate and best friends. The Journal of Experimental Education, 76, 170-189. http://dx.doi.org/10.3200/JEXE.76.2.170-190

Ogoye-Ndegwa, C., Saisi, W., Mengich \& Abidha, O. (2007). Parental participation in pupils' homework in Kenya: In search of an inclusive policy. International Educational Journal, 8(1), 118-126.

Olsen, G., \& Fuller M.L. (2010). The Benefits of Parent Involvement: What Research Has to Say Pearson Allyn Bacon Prentice Hall. Retrieved from http://www.education.com/reference/article/benefits-parentinvolvement-research/

Palm, G., \& Fagan, J. (2008). Father involvement in early childhood programs: Review of the literature. Early Child Development and Care, 178, 745-759. http://dx.doi.org/10.1080/03004430802352137

Paul, L. M., Simons, G. S., \& Fennig, C.D. (Eds.). (2015). Ethnologue: Languages of the World, Eighteenth edition. Dallas. Texas: SIL International.

Sanders, M. G. (1998). The effects of school, family, and community support on the academic achievement of African American adolescents. Urban Education, 33(3), 385-409. http://dx.doi.org/10.1177/0042085998033003005

Shaver, A. V., \& Walls, R. T. (1998). Effect of Title I parent involvement on student reading and mathematics achievement. Journal of Research and Development in Education, 31(2), 90-97.

Tornblad, H., \& Widell, K. (2014). "Education is the key of life" A Minor Field Study about the discourses of parental involvement in two Tanzanian primary schools. Bachelor Degree Project in teacher education. Retrieved from http://www.divaportal.org/smash/get/diva2:695855/FULLTEXT01.pdf

U.S. Department of Education. (1994, September). Strong families, strong schools: Building community partnerships for learning. Washington, DC: Author.

Wabike, P. (2012). 'Arming the Rebels for Development': Parental Involvement among Fishing Communities in Tanzania. Africa Development, 37(3), 171-191.

Walker, J. M. T., Ice, C. L., Hoover-Dempsey, K., \& Sandler, H. M. (2011). Latino parents' motivations for engagement in their children's schooling. The Elementary School Journal, 111, 409-429. http://dx.doi.org/10.1086/657653

Zedan, R. F. (2012). Parents' involvement among the Arab ethnic minority in the State of Israel. School Community Journal, 22(2), 161-182. 